\title{
Phytochemical Analysis of Some Selected Indigenous Fruits Collected from Lokogoma-Abuja, Nigeria
}

\author{
Akilu Mariya ${ }^{1,}$, , Abdulrasheed Hadiza Haruna ${ }^{1}$, Akilu Zakari Babangida ${ }^{2}$ \\ ${ }^{1}$ Life Sciences Division, Engineering and Space Systems Department, National Space Research and Development Agency, Abuja, Nigeria \\ ${ }^{2}$ Department of Biochemistry, Faculty of Life Sciences, Ahmadu Bello University, Zaria, Nigeria
}

Email address:

makilu75@gmail.com (Akilu M.), hadizaabdulrasheed@gmail.com (Abdulrasheed H. H.), zackzony1@gmail.com (Akilu Z. B.)

${ }^{*}$ Corresponding author

\section{To cite this article:}

Akilu Mariya, Abdulrasheed Hadiza Haruna, Akilu Zakari Babangida. Phytochemical Analysis of Some Selected Indigenous Fruits Collected from Lokogoma-Abuja, Nigeria. Journal of Diseases and Medicinal Plants. Vol. 6, No. 2, 2020, pp. 50-55.

doi: $10.11648 /$ j.jdmp.20200602.14

Received: July 1, 2020; Accepted: July 14, 2020; Published: July 28, 2020

\begin{abstract}
Fruits, vegetables, and other plant-based foods are rich in bioactive phytochemicals that may provide desirable health benefits beyond basic nutrition to reduce the risk of the development of chronic diseases (Liu, 2004). This study focuses on determining the presence of phytochemical components in Citrillus lanatus (Watermelon), Musa acuminate (Banana), Psidium guajava (Guava) and Solanum lycopersicum (Tomato) samples collected from a location in Abuja, FCT. The set objectives were achieved using the standard laboratory procedures as sourced from literature. To determine the presence of phytochemical components responsible for the medicinal properties, a qualitative screening checking for ten (10) known phytochemicals was conducted for each fruit extract. The Phytochemicals screened for were Tannins, Saponins, Alkaloids, Flavonoids, Glycosides, Terpenes, Steroids, Phenols, Resins and Anthraquinones. All sampled fruit revealed the presence of a number of the phytochemicals checked, but no fruit sample tested positive for all phytochemicals tested. The Citrillus lanatus was the only sample to test positive for Flavonoids and negative for Anthraquinones. The phytochemicals found in these fruits have a wide range of therapeutic indications with a great variety of biological properties such as antioxidant, provitamin, antibacterial, antiviral, anticancer and anti-inflammatory activities. The present data suggests that the crude ethanolic extracts of the sample fruits are potential sources of phytochemicals that could be of great importance to the health and nutrition of humans and in the treatment of various diseases.
\end{abstract}

Keywords: Phytochemicals, Citrillus Lanatus, Musa Acuminate, Psidium Guajava, Solanum Lycopersicum

\section{Introduction}

Medicinal plants remain nature's reservatory of biological active compounds with biochemical and therapeutic properties [1]. These biological compounds found in medicinal plants are called Phytochemicals, they are naturally occurring chemical compounds in plants, which protect plant cells from environmental hazards such as pollution, stress, drought, UV exposure and pathogenic attack [2]. These compounds are considered secondary plant metabolites and have shown to possess various biological effects, which provide the scientific base for the use of herbs in the traditional medicine of many ancient communities. They have been described as antibiotic, antifungal and antiviral and therefore are able to protect plants from pathogens [3]. It has been estimated that $14-28 \%$ of higher plant species are used medicinally and that $74 \%$ of pharmacologically active plant derived components were discovered after following up on ethno-medicinal use of the plants [4]. Phytochemicals are used for various purposes such as pharmaceuticals, agrochemicals, flavors, etc., and their chemical structures are composed of phytochemicals such as phenolics, alkaloids, saponins and terpenoids [5].

Fruits are commonly consumed for their nutrients, and some are used as medicine. The medicinal properties of fruits are closely related to their available phytochemicals, as well as antioxidants. About 200,000 phytochemicals are known so far and 20,000 of them have been identified as originating from fruits, vegetables and grains [5]. Besides the fruit, the 
bark, leaves, stem, root, twig, and sap of plants have been used as ingredients for traditional medicine. These parts have been widely used as folk medicines by locals for treating several diseases, including cough, fever, asthma, diarrhea, indigestion, and skin diseases [6]. In modern medicine, extracts of different parts of the plant including the fruit have been further employed for their medicinal benefits, as antifungal, antimicrobial, anti-atherosclerotic, antihypercholesterolemic, anti-leukemic, anti-clastogenic, and anti-proliferative agents [7].

Watermelon fruit (Citrillus lanatus) is highly cultivated worldwide and known for its large edible fruit, which is a berry with a hard rind and no internal divisions. The fruit can be eaten raw or pickled, and the rind is edible after cooking. Watermelon is a sweet, commonly consumed fruit of summer, usually as fresh slices, diced in mixed fruit salads, or as juice $[8,9]$. Watermelon juice can be blended with other fruit juices or made into wine [10]. It is a fruit that contains nutrients and phytochemicals reported to be beneficial to human health $[11,12]$. It is also a good source of vitamins B, $\mathrm{C}$, and $\mathrm{E}$ as well as minerals such as phosphorus, magnesium, calcium, and iron [13]. Consumption of watermelon is beneficial to consumers as it shows many positive biological effects, which are mostly connected to being fat-free, cholesterol-free, low in sodium, rich in minerals and phytochemicals [14]. In addition, epidemiological studies have demonstrated that the fruit possesses antioxidants with anti-inflammatory, antihypertensive properties as well as a protective effect against carbon tetrachloride-induced toxicity $[11,12]$.

Banana (Musa acuminate) is one of the most widely distributed and consumed fruit in the tropical and subtropical countries $[15,16]$. The fact that banana is used in the preparation of many commercial dietary supplements and processed food products highlights the importance of studies on the phytochemical and antioxidant studies of the most popular and widely consumed varieties of banana in a region [16]. Although bananas are commonly thought to supply exceptional potassium content $[17,18]$ their actual potassium content is relatively low per typical food serving at only $8 \%$ of the Daily Value. In exhaustive reviews, [19, 20] have reported that banana is rich in many bioactive compounds, such as carotenoids, flavonoids, phenolics, amines, vitamin C, and vitamin $\mathrm{E}$ having antioxidant activities to provide many human health benefits [21].

Psidium guajava (Guava) fruit is a common tropical fruit (berry) cultivated in many tropical and subtropical regions [22]. It is originated from Mexico or Central America and due to its health benefits it is grown abundantly in various countries that include Bangladesh, China, India, Nigeria, Thailand and Philippines [23]. Since the 1950s, guavas, particularly the leaves, have been studied for their constituents, potential biological properties and history in folk medicine [24]. According to [25], guava is considered a multipurpose medicinal tree similar to Mangifera indica and Azadirachta indica because of myriad medicinal values from various parts viz., leaf, roots, bark and fruit [26, 27, 28]. Its fruits are rich in antioxidants, vitamin $\mathrm{C}$, potassium, and fiber, this remarkable nutrient content gives the fruit many health benefits. Guavas are one of the richest food sources of vitamin $\mathrm{C}$, in fact one guava provides about double the Reference Daily Intake (RDI) for vitamin C, this is almost twice the amount you would get from eating an orange [29]. Vitamin C plays an important role in maintaining a healthy immune system [30]. It's also linked to antimicrobial benefits This means that it helps kill off bad bacteria and viruses that can lead to infections [30].

Tomato is the edible, often red, berry of the plant Solanum lycopersicum [31], commonly known as a tomato plant, which belongs to the nightshade family, Solanaceae. Tomatoes are the major dietary source of the antioxidant lycopene, which has been linked to many health benefits, including reduced risk of heart diseases and cancer [32, 33]. Including tomatoes in the diet cam help protect against cancer, maintain healthy blood pressure and reduce blood glucose in diabetics [34]. Cooked or raw tomato is consumed in the various parts of the world in different forms in curries, sauces, salads etc. [35]. Consumption of tomatoes exert positive effects on human health and is known for anti-inflammatory, anti-genotoxic, anti-mutagenic, anti-proliferative and chemo-preventive activities [36-40].

Medicinal plant-based drugs have the advantage of being simple, effective and exhibit broad-spectrum activity. The majority of people, especially those living in rural communities, depend heavily on folklore medicine for their primary healthcare owing to their ready availability, relative safety and affordability over modern medicine [1]. The availability of different varieties of fruits and the cultures in different regions affect the dietary lifestyles of people all over the world. It is necessary to profile the phytochemicals present in indigenous fruits and vegetables to better provide alternative treatments for different diseases common in these regions.

\section{Materials and Methods}

\subsection{Plant Materials}

The Citrillus lanatus (watermelon) fruit, Musa acuminate (banana) fruit, Psidium guajava (guava) fruit and Solanum lycopersicum (tomato) fruits were collected from the Lokogoma market, Abuja.

\subsection{Sample Preparation}

The fruit samples were washed thoroughly under running water, chopped into uniform sizes and dried in an oven at $60^{\circ} \mathrm{C}$ until adequately dehydrated. Using a mortar, pestle, miller and grinder, the fruits were homogenized into powder form and stored in airtight bottles for phytochemical screening.

\subsection{Extraction of Plant Materials}

The fruit samples were macerated separately in Ethanol (solvent) for 24 hours. After which it was filtered using 
suction filtration. The filtrate of each sample was further concentrated using the Rotary Evaporator at reduced temperature and pressure. The concentrated extracts were finally dried on the water bath and transferred to sample bottles for further analysis.

\subsection{Preliminary Phytochemical Screening of Different Extract Samples}

Chemical tests for the screening and identification of bioactive chemical constituents in the fruit extracts were carried out with the extracts using standard clinical laboratory methods.

\subsubsection{Test for Tannins}

$3 \mathrm{~g}$ of each powdered samples was boiled in $50 \mathrm{ml}$ of distilled water for 1 minute on a hot plate. The mixture was filtered and the resulting filtrate was used to carry out the following test for tannins.

i. Ferric Chloride Test

A portion of the water extract was diluted with distilled water in a ratio of 1:4 and a few drops of $10 \%$ ferric chloride was added (a blue or green color indicates the presence of tannins).

ii. Lead Sub-Acetate Test

To $1 \mathrm{ml}$ of the resulting filtrate, 3 drops of lead sub-acetate solution was added (production of brown precipitate indicates the presence of tannins).

iii. Ferric Ammonium Citrate Test

To $1 \mathrm{ml}$ of the water extract, $0.25 \%$ ferric ammonium citrate solution was added. To the mixture, sufficient solid sodium acetate was added to adjust the solution of $\mathrm{pH} 8$ using an indicator paper. The solution was boiled on a water bath and filtered (a dark green precipitate indicates the presence of tannins).

\subsubsection{Test for Saponins}

\section{i. Froth Test}

To a small quantity of the powdered sample, $95 \%$ ethanol was added and boiled. The mixture was filtered and $2.5 \mathrm{ml}$ of the filtrate was added to $10 \mathrm{ml}$ of diluted water in a test tube. The test tube was corked and shaken vigorously for about 30 seconds, it was then allowed to sit for half an hour (Persistent homogenous froth is indicative of the presence of Saponins).

ii. Fehling's solution test

To $2 \mathrm{ml}$ of the samples extract, an equal amount of Fehling's solution. A bluish-green precipitate shows the presence of saponin glycoside.

\subsubsection{Test for Alkaloids}

$3 \mathrm{~g}$ of each powdered sample was added to $50 \mathrm{ml}$ methanol, the mixture was evaporated to dryness. $0.5 \mathrm{~g}$ of the residue was mixed with $10 \mathrm{ml}$ of the $1 \%$ aqueous hydrochloric acid on a water bath. $1 \mathrm{ml}$ each of the filtrate was treated with a few drops of the following reagents:

(1) Mayer's reagent (potassium mercuric iodine solution)

(2) Dragendorff's reagent (potassium bismuth iodine solution)

(3) Wagner's reagent (solution of iodine in potassium iodide)

(4) $10 \%$ tannic acid solution (a solution of picric acid)

Turbidity or precipitation with all of these reagents is indicative of the presence of alkaloids in the extract [41].

\subsubsection{Test for Flavonoids}

$5 \mathrm{~g}$ of each powdered sample was completely de-tanned using acetone. The residue was extracted in warm water after evaporating the acetone on a water bath. The mixture was filtered and the filtrate was used for the following tests:

i. Lead Acetate Test

To $5 \mathrm{ml}$ of the de-tanned water extract, a $10 \%$ lead acetate solution was added. A colored precipitate indicates the presence of flavonoids.

ii. Sodium Hydroxide Test

$5 \mathrm{ml}$ of $10 \%$ sodium hydroxide was added to an equal volume of the de-tanned water extract. A yellow solution indicates the presence of flavonoids.

iii. Shinoda Test

$0.5 \mathrm{~g}$ of each powdered sample was extracted in ethanol by boiling on a water bath for 5 minutes, filtered and cooled. To the filtrate was added four pieces of magnesium filing followed by a few drops of concentrated hydrochloric acid. A pink or red color indicates the presence of flavonoids [42].

iv. Amyl Alcohol Test

$3 \mathrm{~g}$ of teach powdered sample was macerated in $50 \mathrm{ml}$ of $1 \%$ hydrochloric acid and filtered. The filtrate was used for the following tests:

1) $4 \mathrm{ml}$ of the filtrate was shaken with $5 \mathrm{ml}$ of amyl alcohol. Production of a yellow color indicates the presence of free flavonoid aglycones.

2) $10 \mathrm{ml}$ of the filtrate was shaken with $7 \mathrm{ml}$ of amyl alcohol and the mixture was transferred into a separating funnel. The amyl alcohol layer was discarded and the aqueous layer boiled with $10 \mathrm{ml}$ of $10 \%$ hydrochloric acid for 2 minutes. The acidic solution was cooled and divided into two portions. The first portion was shaken with amyl alcohol. Production of a yellow color indicates the presence of a combined flavonoid. To the second portion, magnesium turning was added and the color of the solution was observed [43] (production of a red color indicates the presence of flavanone and flavonol glycoside).

\subsubsection{Test for Glycosides}

i. Test for Cardiac Glycosides

$0.5 \mathrm{~g}$ of each powdered sample was boiled with $10 \mathrm{ml}$ of $95 \%$ alcohol for 2 minutes. The resulting mixture was filtered and cooled. The filtrate was diluted with water and three drops of a strong solution of lead sub-acetate were added. This was mixed thoroughly and filtered. The filtrate was divided into two portions; one portion was kept for further test and the other portion was extracted with $5 \mathrm{ml}$ of chloroform in a separating funnel. The lower chloroform layer was divided into two evaporating dishes, evaporated to dryness and used for the following tests:

ii. Keller- keliani test for deoxy sugars

One of the chloroform residues was dissolved in $1 \mathrm{ml}$ of 
glacial acetic acid containing a trace of ferric chloride solution. The mixture was carefully poured on the surface of $1 \mathrm{ml}$ of Sulphuric acid already contained in a test tube to form a separate layer (reddish-brown color at the interface of the liquid indicates the presence of digitoxase).

iii. Legal Test for Cardenolide aglycone

The second chloroform residue was dissolved in a few drops of pyridine and a few drops of $20 \%$ sodium hydroxide was added. A deep red color indicates the presence of cardenolide aglycone [44].

iv. Kedde test for free or combined cardenolide aglycone

The reserved filtrate was treated with $1 \mathrm{ml}$ of $2 \%$ solution of 3, 5 dinitro benzoic acid in alcohol. The solution was made alkaline with 5\% sodium hydroxide (purple-blue color indicates the presence of the free or combined cardenolide aglycone) [44].

\subsubsection{Test for Terpenes and Sterols}

$5 \mathrm{~g}$ of each powdered sample was extracted by macerating with $50 \mathrm{ml}$ of ethanol $(95 \%)$, each filtered and the filtrates were evaporated to dryness. The residues were dissolved in $10 \mathrm{ml}$ of anhydrous chloroform and then filtered. Each filtrate was divided into two equal portions and the following tests were carried out.

i. Liebermann-Burchard Test

The first portion of the chloroform solution from above was mixed with $2 \mathrm{ml}$ of acetic anhydride, followed by the addition of $1 \mathrm{ml}$ of concentrated Sulphuric acid down the walls of each test tube to form a lower layer. The formation of reddish-violet color at the junction of the two liquids and green color in the chloroform layer indicates the presence of terpenes.

ii. Salkowski's Test

The second portion of the solution was mixed with $2 \mathrm{ml}$ of concentrated Sulphuric acid carefully s that the acid forms a lower layer (a reddish-brown color at the interface indicates the presence of a steroid).

\subsubsection{Test for Resins}

$15 \mathrm{ml}$ of petroleum ether extract was made using $0.1 \mathrm{~g}$ of each powdered sample and filtered into test tubes. An equal volume of copper acetate solution was added to each test tube and shaken vigorously, then allowed to separate (green color indicates the presence of resins).

\subsubsection{Test for Anthraquinone Derivatives}

To show for the presence of free and/or combined anthraquinones:

$0.5 \mathrm{~g}$ of the powdered sample was boiled with $10 \mathrm{ml}$ of $10 \%$ hydrochloric acid for 2 minutes. The extract was filtered. To the filtrate, an equal volume of chloroform was added, the test tube was inverted a couple of times avoiding vigorous shaking. The solution was transferred into a separating funnel and the two layers were allowed to separate. The lower chloroform layer was poured into a clean test tube and the ammonia solution was added shaken. Both layers were again allowed to separate, (a bright pink color in the upper aqueous layer indicates the presence of free and/or combined anthraquinones).

\section{Results and Discussion}

The results of the phytochemical Screening of the fruit Samples were studied, analyzed and presented in Table 1 which shows all the metabolites that were tested for in each sample.

Table 1. Phytochemical screening of fruit samples.

\begin{tabular}{lllll}
\hline Parameters & $\begin{array}{l}\text { Citrillus } \\
\text { lanatus }\end{array}$ & $\begin{array}{l}\text { Musa } \\
\text { acuminate }\end{array}$ & $\begin{array}{l}\text { Psidium } \\
\text { guajava }\end{array}$ & $\begin{array}{l}\text { Solanum } \\
\text { lycopersicum }\end{array}$ \\
\hline Tannins & + & - & - & + \\
Saponins & - & + & + & - \\
Alkaloids & - & + & + & - \\
Flavonoids & - & + & + & + \\
Glycosides & + & - & - & - \\
Terpenes & + & + & - & + \\
Steroids & + & + & - & + \\
Phenols & + & + & + & - \\
Resins & - & - & + & + \\
Anthraquinones & - & + & + & + \\
\hline
\end{tabular}

Key: + Present, - Absent.

Table 1 shows all the metabolites that were tested for in each fruit sample. Positive indicates the presence while negative indicates the absence of the particular constituents or metabolites. Citrillus lanatus tested positive for five (5) phytochemicals namely Tannins, Glycosides, Terpenes, Steroids and Phenols; it was the only fruit to test negative for Flavonoids and Anthraquinones. Musa acuminate showed presence of Saponins, Alkaloids, Flavonoids, Terpenes, Steroids, Phenols and Anthraquinones, and negative for Tannins, Glycosides and Resins. Psidium guajava indicated the presence of Saponins, Alkaloids, Flavonoids, Phenols, Resins and Anthraquinones. It was the only fruit to test negative for the presence of Terpenes and Steroids. Solanum lycopersicum tested positive for the presence of Tannins, Flavonoids, Terpenes, Steroids, Resins and Anthraquinones, and was the only fruit sample to test negative for Phenols.

\section{Conclusion}

More than $80 \%$ of the world population solely relies on medicinal plants for their primary health care needs. Some of these plants are proven to provide symptomatic relief and assist in the prevention of the secondary complication of different diseases, while others are reported to help in regeneration of abnormal cells and in overcoming disease causing pathogens. The healing power of these medically important plants may be due to the presence of various secondary metabolites such as those tested in the study. The results of the present study have shown that the fruit samples tested contain phytochemicals of medicinal importance. It could therefore be inferred that the fruits contain bioactive constituents which can be explored and utilized in the fight 
against diseases.

Scientifically, extra efforts are needed for studies on the beneficial health properties and toxicity effect of these fruits using animal-based (in-vivo) experiments. Due to the variation in the present bioactive phytochemicals in these fruits, attention should be given to study the efficacy of these fruits in combating diseases and turning them into nutraceuticals or basic ingredients for functional food, the bioactive compounds isolated from these fruits could also be used as nutraceuticals and pharmaceutical ingredients.

\section{References}

[1] Oyedemi, S. O.; Bradley, G.; Afolayan, A. J. In vivo and in vitro antioxidant activities of aqueous stem bark extract of Strychnos henningsii (Gilg). Afr. J. Pharm. Pharmacol 2010, 4, 70-78.

[2] Ali AA, Alqurainy F. Activities of antioxidants in plants under environmental stress. The lutein-prevention and treatment for diseases. 2006; 187-256.

[3] Rehab A. Hussein and Amira A. El-Anssary, 2018. "Plants Secondary Metabolites: The Key Drivers of the Pharmacological Actions of Medicinal Plants". November 5th 2018 DOI: 10.5772/intechopen.76139.

[4] Watson, A. A., Fleet, G. W. J., Asano, N., Molyneux, R. J. and Nash, R. J. (2001). Poly-hydroxylated alkaloid -natural occurrence and therapeutic applications. Phytochemistry. 56: 265-295.

[5] Patra AK. Dietary Phytochemicals and Microbes. ISBN 978-94-007-3925-3 ISBN 978-94- 007-3926-0 (eBook). 2012; Springer Dordrecht Heidelberg New York London.

[6] C. Muthu, M. Ayyanar, N. Raja, and S. Ignacimuthu, "Medicinal plants used by traditional healers in Kancheepuram District of Tamil Nadu, India," Journal of Ethnobiology and Ethnomedicine, vol. 2, article 43, 2006.

[7] A. Rizvi, A. Mishra, A. A. Mahdi, M. Ahmad, and A. Basit "Natural and herbal stress remedies: a review," International Journal of Pharmacognosy, vol. 2, no. 4, pp. 155-160, 2015.

[8] "Watermelon". Marketing Resource Center, US Department of Agriculture, Iowa State University. 2017. Retrieved 9 May 2017.

[9] "Top 10 ways to enjoy watermelon". Produce for Better Health Foundation, Centers for Disease Control, US National Institutes of Health. 2017. Retrieved 9 May 2017.

[10] Ogodo, A. C.; Ugbogu, O. C.; Ugbogu, A. E.; Ezeonu, C. S. (2015). "Production of mixed fruit (pawpaw, banana and watermelon) wine using Saccharomyces cerevisiae isolated from palm wine". SpringerPlus. 4: 683. doi: 10.1186/s40064015-1475-8.

[11] Choudhary, B. R.; Haldhar, S. M.; Maheshwari, S. K.; Bhargava, R.; Sharma, S. K. Phytochemicals and Antioxidants in Watermelon (Citrullus Lanatus) Genotypes under Hot Arid Region. Indian J. Agric. Sci. 2015, 85, 414-417.

[12] Ijah, U. J. J.; Ayodele, H. S.; Aransiola, S. A. Microbiological and Some Sensory Attributes of Watermelon Juice and
Watermelon-Orange Juice Mix. J. Food Resour. Sci. 2015, 4, 49-61. DOI: $10.3923 /$ jfrs.2015.49.61.

[13] Romdhane, M. B.; Haddar, A.; Ghazala, I.; Jeddou, K. B.; Helbert, C. B.; Ellouz-Chaabouni, S. Optimization of Polysaccharides Extraction from Watermelon Rinds: Structure, Functional and Biological Activities. Food Chem. 2017, 216, 355-364. DOI: 10.1016/j.foodchem.2016.08.056.

[14] Jumde, A. D.; Shukla, R. N.; Gousoddin. Development and Chemical Analysis of Watermelon Blends with Beetroot Juice during Storage. Int. J. Sci. Eng. Technol. 2015, 4, 2395-4752.

[15] Mohammad, Z. I., \& Saleha, A. (2011). Musa paradisiaca L. and Musa sapientum L.: A Phytochemical and Pharmacological Review. Journal of Applied Pharmaceutical Science, 01, 14-20.

[16] Guyle'ne Aurorea, Berthe, P., \& Louis, F. (2009). Bananas, raw materials for making processed food products. Trends in Food Science \& Technology, 20, 78-91.

[17] Gordon Edwards (2019). "About radioactive bananas" (PDF). Canadian Coalition for Nuclear Responsibility. Retrieved April 24, 2019.

[18] Kraft S (August 4, 2011). "Bananas! Eating Healthy Will Cost You; Potassium Alone $\$ 380$ per Year". Medical News Today. Archived from the original on October 25, 2014. Retrieved October 25, 2014.

[19] Pereira, A., Maraschin, M. (2015). Banana (Musa spp) from peel to pulp: Ethno-pharmacology, source of bioactive compounds and its relevance for human health. Journal of Ethno-pharmacology, 160: 149-163.

[20] Singh, B., Singh, J. P., Kaur, A., Singh, N. (2016). Bioactive compounds in banana and their associated health benefits - A review. Food Chemistry, 206: 1-11.

[21] Jiwan S Sidhu, Tasleem A Zafar. "Bioactive compounds in banana fruits and their health benefits". Food Quality and Safety, Volume 2, Issue 4, December 2018, Pages 183-188.

[22] Judd, WS; Campbell, CS; Kellogg, EA; Stevens, PF; Donoghue, MJ (2002). Plant systematics, a phylogenetic approach. Sinauer Associates, Inc. pp. 398-399. ISBN 0878934030 .

[23] Uzzaman S, Akanda KM, Mehjabin S, Parvez GMM. A short review on a nutritional fruit: guava. Opn Acc Tox Res. 2018; 1: $1-8$.

[24] De Boer HJ, Cotingting C (2014). "Medicinal plants for women's healthcare in southeast Asia: a meta-analysis of their traditional use, chemical constituents, and pharmacology". J $\begin{array}{llll}\text { Ethnopharmacol. } & 151 & \text { (2): } & 747-67 .\end{array}$ 10.1016/j.jep.2013.11.030. PMID 24269772.

[25] Shaik Shaheena, Anjani Devi Chintagunta, Vijaya Ramu Dirisala and N. S. Sampath Kumar. "Extraction of bioactive compounds from Psidium guajava and their application in dentistry." AMB Expr 9, 208 (2019). doi.org/10.1186/s13568019-0935-x.

[26] Sravani D, Aarathi K, Sampath Kumar NS, Krupanidhi S, VijayaRamu D, Venkateswarlu TC. In vitro anti-inflammatory activity of Mangifera indica and Manilkara zapota leaf extract. RJPT. 2015; 8: 1477-1480. 
[27] Naidu NK, Vijaya Ramu V, Sampath Kumar NS. Antiinflammatory and anti-helminthic activity of ethanolic extract of Azadirachta indica leaves. IJGP. 2016; 10: S1-S4.

[28] Raju NV, Sukumar K, Babul Reddy G, Pankaj PK, Muralitharan G, Annapareddy S, Sai DT, Chintagunta AD. Invitro studies on anti-tumor and antimicrobial activities of methanolic kernel extract of Mangifera Indica L. cultivar Banganapalli. Biomed Pharmacol J. 2019; 12: 357-362. doi: 10.13005/bpj/1648.

[29] Self-Nutrition Data, 2018. "Guavas, Common, raw Nutrition Facts and Calories". https://nutritiondata.self.com/facts/fruitsand-fruit-juices/1927/2.

[30] Shaik-Dasthagirisaheb YB, Varvara G, Murmura G, et al., 2013. Role of vitamins D, E and C in immunity and inflammation. J Biol Regul Homeost Agents. 2013; 27 (2): 291-295.

[31] "Tomato". Encyclopaedia Britannica. 4 January 2018. Retrieved 15 January 2014.

[32] Adda Bjarnadottir, 2019. "Tomatoes 101: Nutrition Facts and Health Benefits". Healthline Nutrition. March 25, 2019. https://www.healthline.com/nutrition/foods/tomatoes

[33] Erica N. Story, Rachel E. Kopec, Steven J. Schwartz and G. Keith Harris, 2010. An Update on the Health Effects of Tomato Lycopene. Annu Rev Food Sci Technol. 2010; 1: 189-210.

[34] Ware Megan, 2017. "Everything you need to know about tomatoes". Medical News Today. https://www.medicalnewstoday.com/articles/273031.

[35] Poonam Chaudhary, Ashita Sharma, Balwinder Singh and Avinash Kaur Nagpal. Bioactivities of Phytochemicals present in Tomato. Journal of Food Science and Technology. 2018; 55 (8): 2833-2849.

[36] Rafi MM, Yadav PN, Reyes M. Lycopene inhibits LPSinduced pro-inflammatory mediator inducible nitric oxide synthase in mouse macrophage cells. J Food Sci. 2007; 72 (1): S069-S074.

[37] Scolastici C, de Lima RA, Barbisan LF, Ferreira ALDA, Ribeiro DA, Salvadori DMF. Lycopene activity against chemically induced DNA damage in Chinese hamster ovary cells. Toxicol In Vitro. 2007; 21 (5): 840-845.

[38] Scolastici C, de Lima RA, Barbisan LF, Ferreira ALDA, Ribeiro DA, Salvadori DMF. Antigenotoxicity and antimutagenicity of lycopene in HepG2 cell line evaluated by the comet assay and micronucleus test. Toxicol In Vitro. 2008; 22 (2): 510-514.

[39] Polívková Z, Šmerák P, Demová H, Houška M. Antimutagenic effects of lycopene and tomato purée. J Med Food. 2010; 13 (6): 1443-1450.

[40] Feng D, Ling WH, Duan RD. Lycopene suppresses LPSinduced NO and IL- 6 production by inhibiting the activation of ERK, p38MAPK, and NF- $\mathrm{BB}$ in macrophages. Inflamm Res. 2010; 59 (2): 115-121.

[41] Sofowora, A., 1993. Medicinal Plants and Traditional Medicine in Africa. 2nd Edn. Spectrum Books Ltd., Ibadan, Nigeria, ISBN-13: 9782462195 , Pages: 289.

[42] Geissmann, T. A.: The Chemistry of Flavonoid Compounds; Pergamon Press, Oxford, London, New York, Paris; 1962; VIII.

[43] Prod, J. N., Resour, P., Zohra, S. F., Meriem, B., Samira, S., and Alsayadi, M. (2012) 'Phytochemical Screening and identification of some compounds from Mallow', 2 (4), pp. 512-516.

[44] Sofowora, A., 1996. Medicinal Plant and Traditional Medicine in Africa. 2nd Edn. Spectrum Books, Ibadan, Nigeria, pp: 112.

[45] Liu RH. Potential synergy of phytochemicals in cancer prevention: mechanism of action. J Nutr. 2004; 134: 3479S-85S. 